\title{
Otredades y permanencias: fotografía histórica y exposición contemporánea del bosque y el indígena amazónico
}

\section{Otherness and Continuities: Historical Photography and Contemporary Exhibitions of Amazonian Indigenous Peoples and Forests}

\author{
Juan Carlos La Serna' \\ Universidad Nacional Mayor de San Marcos \\ Universidad de Lima
}

\section{Valeria Biffi ${ }^{2}$}

Pontificia Universidad Católica del Perú

\section{RESUMEN}

El renovado interés que la fotografía histórica sobre la Amazonía peruana ha despertado en las ciencias sociales, así como el constante uso que distintos proyectos culturales y artísticos hacen de esta fuente, nos anima a explorar el valor que un conjunto de fotografías históricas, producidas entre finales del siglo xIx y las primeras dos décadas del siglo xx, han adquirido en la construcción de una narrativa contemporánea sobre la población y el territorio selvático. El análisis de estas fotografías cobra mayor relevancia en el contexto actual, marcado por el debate público surgido ante la creciente presión que el Estado peruano y diversos agentes externos ejercen sobre el espacio amazónico. En tal sentido, la temprana representación visual del indígena y del bosque, puesta en escena en un conjunto de exposiciones fotográficas recientes, nos permite reflexionar sobre la manera en que la Amazonía viene siendo integrada dentro de los imaginarios nacionales contemporáneos.

\section{Palabras clave:}

Amazonía / Archivo / Exposición / Fotografía / Indígena

\section{ABSTRACT}

The renewed interest that historical photography of the Peruvian Amazon has awakened in the social sciences and cultural and artistic projects encouraged us to explore the importance that these images, produced between the late 19th and the early 20th century, have acquired in the construction of a contemporary narrative regarding the Amazonian indigenous peoples and the Amazonian forest. The analysis of these photographs is even more relevant in the current setting, marked by the public debate emerged at the increasing pressure that the Peruvian government and external agents have on the Amazon region and its natural resources. In this regard, early visual representations of the Amazonian indigenous peoples and the Amazonian forest, shown in recent photo exhibitions, allow us to reflect on how the Amazon is being integrated into contemporary national imaginary.

\section{Keywords:}

Amazon / Archive / Exhibit / Photography / Indigenous

1 Juan Carlos La Serna es historiador por la Universidad Nacional Mayor de San Marcos. Trabaja como docente del Programa de Estudios Generales de la Universidad de Lima y es investigador en la Dirección de Patrimonio Inmaterial del Ministerio de Cultura. Correo: jlaserna@ulima.edu.pe

2 Valeria Biffi es antropóloga por la Pontificia Universidad Católica del Perú; tiene un máster en sociología por la London School of Economics and Political Science. Se desempeña como docente de la Maestría de Antropología Visual en esta misma universidad. Correo: vbiffi@ pucp.edu.pe 


\section{Introducción}

Desde finales de la década de 1860 el mejoramiento de los procesos fotográficos permitió que una serie de técni$\cos$ y artistas, por iniciativa particular, o incorporados a comisiones estatales, produjeran los primeros clichés fotográficos con motivos amazónicos. Con los años, estas tempranas "expediciones fotográficas" fueron generando un conjunto de imágenes que, expuestas en diversos escenarios y ante distintos públicos, contribuyeron a la domesticación visual de la frontera interna peruana.

Paralelamente, el desarrollo de las tecnologías de impresión —desde la litografía al fotograbado- permitió el consumo masivo de estas imágenes a través de la prensa nacional, fortaleciendo los discursos de los sectores modernizantes que incidieron -en la necesidad de articular los territorios amazónicos al proyecto nacional imaginado desde las élites urbanas. De este modo, los clichés reproducidos en la prensa escrita permitieron a la naciente opinión pública peruana una aproximación artificial al indígena y al territorio amazónico, mediante una especie de exotismo doméstico.

En principio, la fotografía fue un elemento destacado dentro de las tareas de objetivación y comprobación empírica, herramienta inseparable de las exploraciones a los territorios selváticos todavía inhóspitos, ofreciendo la posibilidad de satisfacer la obsesión científica de medir y clasificar la alteridad, al tiempo que se convertía en expresión fáctica del esfuerzo de los sectores modernizantes y positivistas por nacionalizar la Amazonía. El desarrollo de nuevas técnicas de impresión favoreció la incorporación y circulación de la fotografía en tarjetas postales, textos y publicaciones periódicas impresas, lo que permitió la masificación de estas imágenes alrededor de diversos circuitos culturales, intelectuales y comerciales.

En los últimos años, exposiciones fotográficas organizadas en la ciudad de Lima han hecho un uso profuso de algunas de estas tempranas fotografías del bosque para retratar el pasado de las poblaciones indígenas y su relación con el resto de la sociedad peruana. Desde una mirada al corpus visual, nos interesa responder estas preguntas: ¿cómo se leen las fotos del pasado como documentos históricos? ¿Cuáles son los efectos que tiene la reapropiación de fotografías históricas con respecto a la población indígena y el territorio amazónico?

Para este documento nos basaremos en muestras específicas realizadas en la ciudad de Lima entre los años 2003 y el 2014:

- $\quad$ Serpiente de agua. La vida indígena en la Amazonía, en la Estación Cultural Desamparados, hoy Casa de la Literatura (2003), donde fueron exhibidas fotografías de Charles Kröehle y de Luis Alviña.

- La Amazonía de Charles Kröehle. Fotos y postales de fines del siglo xIx y comienzos del xx, en el Centro Cultural Inca Garcilaso (2010), exposición organizada por el Ministerio de Relaciones Exteriores y el programa cultural Amo-Amazonía con postales de las colecciones de Humberto Currarino y Augusta Alfageme.

- Imágenes e imaginarios de la época del caucho (2012) del Centro Cultural Garcilaso de la Vega / Ministerio de Relaciones Exteriores; organizada por el Centro Amazónico de Antropología y Aplicación Práctica (CAAAP), International Work Group for Indigenous Affairs (IWGIA) y la Organización de Estados Iberoamericanos, con fotografías de la colección de Alberto Chirif.

- Álbum de viaje. Fotografías de la Comisión Consular al Putumayo $y$ afluentes, 1912, en el Centro Cultural de España (2014), organizado por el CAAAP, IWGIA, Organización de Estados Americanos y la Embajada de España, con motivo de la publicación del álbum, con fotografías de Silvino Santos.
- Julio C. Arana. Álbumes fotográficos inéditos, en el Seminario de Historia Rural Andina de la Universidad Nacional Mayor de San Marcos (2014), exposición organizada por este seminario con los álbumes de la colección del historiador Pablo Macera, los que incluyen fotografías familiares y vistas de la región cauchera del Putumayo tomadas por Silvino Santos.

Cabe anotar que la exploración visual de este documento está basada únicamente en el análisis de la producción, selección y exhibición de imágenes. No hemos contemplado el estudio de la audiencia que, de ser el caso, permitiría comprender el proceso de consumo en sí.

\section{El bosque y las tecnologías de la imagen}

Las primeras fotografías conocidas sobre la Amazonía peruana están fechadas hacia 1868-1869 y corresponden a los clichés generados por dos comisiones de exploración geográfica establecidas por el gobierno peruano. La primera de ellas, la Comisión Hidrográfica del Amazonas, creada en 1867, y la segunda, la Comisión Exploradora al Chanchamayo, creada en diciembre de 1868. Un tercer caso en el cual la fotografía se incorpora como parte integral de las comisiones de exploración científica a la montaña fue la Fuerza Expedicionaria al Madre de Dios, en 1873, organizada por el prefecto del Cusco, Baltasar La Torre, la cual recorrió las selvas adyacentes a su jurisdicción.

Paralelamente a las iniciativas estatales por construir un corpus fotográfico sobre la Amazonía, una serie de actores privados fueron generando sus propios materiales a partir de sus recorridos en el bosque. También, hacia finales de la década de 1860 , el fotógrafo alemán Albert Frisch reco- 
rrió la Amazonía brasileña, introduciéndose en el territorio fronterizo peruano. Más adelante, a finales de la década de 1880, se destacó el trabajo conjunto de los fotógrafos Charles Kröehle y Georg Huëbner. Asimismo, viajeros de finales del siglo xIX, como Charles Wiener u Olivier Ordinaire, también utilizaron aparatos fotográficos en sus exploraciones, generando imágenes que fueron incorporadas en distintas publicaciones en el extranjero.

Para inicios del siglo xx, la producción de imágenes se multiplicó, una vez que las rutas comerciales y turísticas abiertas en la región empezaron a ser constantemente transitadas. Para estos andarines, la cámara y el registro fotográfico se convirtieron en elementos inherentes a la experiencia de viaje. Asimismo, una serie de instituciones privadas, que comulgaron con el Estado y las élites políticas e intelectuales en su proyecto de dominio territorial, fueron estableciéndose en diversas regiones de la Amazonía peruana, generando sus propios materiales fotográficos. Un caso especialmente significativo son las imágenes elaboradas para el empresario y político Julio César Arana, las cuales fueron utilizadas profusamente en su defensa frente las numerosas acusaciones de explotación sobre la población indígena en sus caucherías del Putumayo (Chirif y Cornejo, 2009; Flores, 2012). Al igual que otras empresas científicas, comerciales y extractivas en la selva peruana, Arana colaboró activamente en la publicidad estatal dedicada a la explotación de la riqueza amazónica.

Con relación al territorio, el conjunto de fotografías generado durante esta época reproduce el discurso amazonista en boga: asumir el progreso del país a partir del usufructo de un territorio, tan rico como extenso. Ello, por medio de la colonización y su articulación merced a efectivos sistemas viales que pudieran unir el bosque al resto del país, en especial, a la capital. Así, las fotografías ofrecieron un correlato visual de las primeras experiencias de colonización agrícola promovida por el Estado con población europea (Pozuzo, Oxapampa, Chanchamayo-Perené), iniciativas especialmente destacadas

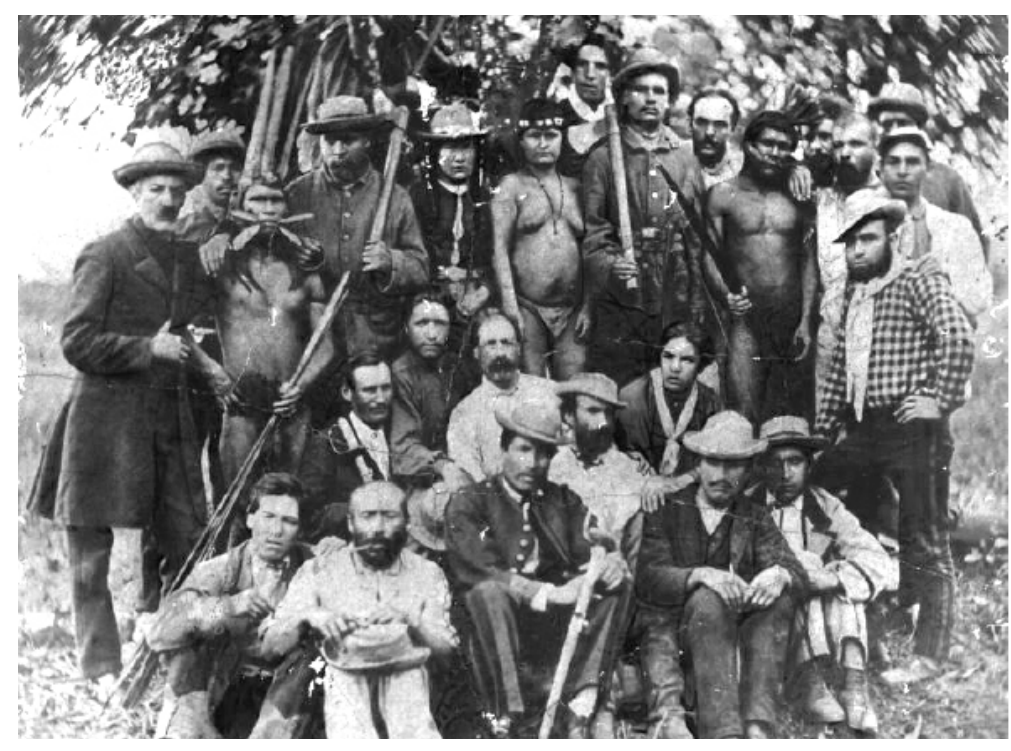

Figura 1. Miembros de la Comisión La Torre con indígenas huarayos. Fotografía de Luis Alviña, 1873. Colección Jean-Pierre Chaumeil. Imagen ampliada, al parecer, para ser exhibida en la Exposición Departamental del Cusco (1897) y donde se rindió homenaje al desaparecido explorador Baltasar La Torre. La fotografía, en tal sentido, es parte de la mitificación que alcanzó esta expedición a la montaña del Cusco por parte de la élite política e intelectual regional. Dice la reseña original: "Expedición del Coronel La Torre, Prefecto del Cuzco, al Madre de Dios con tres huachipairis, vista tomada en la pampa de Ccosñipata. Año 1873. Masacrados por huachipaires en el río Carbón.- Nota.- Murieron todos menos el fotógrafo."

en las publicaciones oficiales y la prensa escrita (La Serna, 2013).

Del mismo modo, resaltan los trabajos de vialidad, a fin de establecer caminos que uniesen la ciudad de Lima a los ríos navegables, y, desde este punto, alcanzar el puerto de lquitos, la próspera capital cauchera peruana. Por último, la insistencia en destacar la labor civilizadora y pacificadora de las fuerzas militares y órdenes religiosas entre la población indígena. Al tiempo que las representaciones del territorio amazónico promovían su domesticación por medio de la técnica y el conocimiento científico (colonización, extracción de recursos, construcción de caminos, ferrocarriles y demás obras de ingeniería), las impresiones que dejan muchos observadores de la época son que las prácticas económicas, políticas y sociales de la población indígena son expresiones de salvajismo y por tanto uno de los grandes obstáculos para la consecución de Amazonía (Biffi, 2012).

\section{La prensa y la temprana exposición de la imagen del bosque}

Una vez generados los primeros materiales fotográficos, instituciones públicas y agentes privados se dedicaron a divulgar estas imágenes en diversos públicos, nacionales y extranjeros, foros inicialmente exclusivos pero que, con el tiempo, fueron masificándose. Tempranamente, en el siglo XIX, estas fotografías fueron comercializadas como cartas de visita; en otros casos, fueron reproducidas en publicaciones y en la prensa, mediante litografías 0 fotograbados partir de fotografía. En tal sentido, las opciones de reproducción estaban supeditadas a las tendencias y los objetivos modernizadores en la 
tecnologías del momento. Este sería, por ejemplo, de las fotografías generadas por las tempranas comisiones de exploración amazónica, la Comisión Hidrográfica del Amazonas, la Expedición al Chanchamayo y la Expedición al Madre de Dios, las cuales fueron incorporadas en publicaciones —algunas litografiadas y otras en albúmina acoplada a los textos- 0 reproducidas en cartas de visita y distribuidas en los estudios fotográficos de la capital.

Así, se destaca el valor que la fotografía, litografía y demás técnicas de reproducción de documentos visuales alcanzó en el proceso de visibilización de la Amazonía dentro de los planteamientos políticos y la opinión pública nacional desde finales del siglo xIx en adelante. Conjuntamente con los discursos positivistas y regeneracionistas de la política, economía y vida social, las élites modernizantes peruanas se valieron de los medios de representación visual a fin de reproducir sus proyectos alrededor de colectivos sociales y grupos económicos cada vez más amplios.

Para inicios del siglo xx, las innovaciones tecnológicas alcanzadas en la prensa peruana permitieron ampliar los espacios de divulgación de las imágenes amazónicas, que empezaron a ser consumidas por un creciente público citadino, el cual, a su vez, se expandió como producto de una mayor alfabetización y el crecimiento de las clases medias y sectores populares urbanos. Así, se destaca la importancia que alcanzaron los medios impresos limeños en la construcción visual del bosque amazónico ante una naciente opinión pública capitalina, mediante secciones como del interior, de pro- vincias o el Perú pintoresco, donde se reprodujeron reseñas de los viajes de exploración, apertura de caminos 0 recorridos científicos, relatos que fueron acompañados de imágenes realizadas por viajeros y comisionados (La Serna, 2015).

De este modo, los grabados aparecidos en la prensa, fueron creando un conjunto de tópicos comunes con el cual se hacía referencia al territorio y la población amazónicos: el proceso de transformación de una tierra ignota, desconocida y amenazante, a un espacio domesticado, dominado por medio de caminos y el asentamiento de colonias y hombres de "espíritu industrioso". Este proceso de amansamiento del territorio se repitió al momento de plasmar al sujeto amazónico, el cual, si bien seguía apareciendo como manifestación de una otredad absolutamente extraña, debía transmutarse a fin de consolidar, visualmente, los proyectos políticos aplicados por el Estado, que apostó por su progresiva inserción en los espacios productivos y comerciales abiertos en este territorio.

Paralelamente, se utilizaron otras estrategias de divulgación de contenidos visuales, las exposiciones públicas. Por ejemplo, la creación del Ministerio de Fomento, en 1896, institución que tuvo entre sus propósitos el desarrollo de las políticas con relación al oriente peruano, promovió diversos escenarios de exposición de imágenes y contenidos amazónicos. Con este objetivo, financió exhibiciones, como la de 1897, que pusieran "al alcance del público la región de la montaña, que en breve será comunicada por camino definitivo con los puertos fluviales del Oriente (...) [a fin de] propagar el conocimiento de esas regiones y provocar hacia ellas una corriente de inmigración espontanea"3. Asimismo, el Ministerio de Relaciones Exteriores realizó una serie de esfuerzos a fin de promover, mediante publicaciones, conferencias y exposiciones internacionales, una imagen del bosque para el público-empresario europeo y norteamericano: territorio cuyas inmensas riquezas esperan la inversión de emprendedores foráneos ${ }^{4}$.

En este sentido, una estrategia de divulgación fueron los álbumes fotográficos compuestos ex profeso para su exposición ante públicos extranjeros. Así, en enero de 1899 la Dirección de Fomento resolvió la elaboración de un álbum sobre las diversas regiones, recursos e industrias el Perú, que debía incorporar una colección completa de vistas de la Vía del Pichis -el primer proyecto vial trasamazónico, que unía el Callao con Iquitos - para luego ser remitido al pabellón peruano en la Exposición Universal de París de 1900. El álbum, titulado República Peruana 1900, se compuso, en su sección amazónica, de imágenes seleccionadas de las colecciones existentes en los archivos gubernamentales y conocidos clichés que algunos fotógrafos, vinculados a las facciones políticas en el gobierno, generaron con anterioridad, entre ellos Charles Kröehle y Federico Remy ${ }^{5}$, destacándose, además de tipos indígenas, diversas imágenes sobre caminos y la población colona de la montaña.

Del mismo modo, hacia marzo de 1911, el ingeniero de la vía del Pichis, Rodolfo Zavala, contrató a Carlos Meyer, fotógrafo establecido en la colonia de La Merced (Chanchamayo), para elaborar

3 “Exhibición panorámica de vistas de la Montaña”. Resolución Suprema del 16 de enero de 1897 (Larrabure, 1905, pp. 476 477). Entre julio y agosto de ese mismo año, la prefectura de Cusco organizó la Exposición Departamental del Cusco, evento en el que se expusieron al público fotografías vinculadas a la expansión oriental del Cusco, como las vistas de la expedición al Madre de Dios (1873), fotografías de indígenas selváticos llevados al Cusco para su exhibición y vistas realizadas por el explorador y hacendado Manuel Santiago Arróspide sobre la región del Paucartambo y el Madre de Dios.

4 Como antecedente al uso de la fotografía en la publicidad destinada a promover, en el extranjero, la colonización y la inversión de capitales en la montaña, podemos señalar algunos documentos que, merced a funcionarios consulares, llegaron a circular entre empresarios y potenciales inmigrantes europeos, como la obras de Antonio Raimondi (1880) y Carlos Fry (1889), ambos con grabados en base a fotografías. La temprana obra de publicidad escrita por el cónsul peruano Herbert Guillaume en Southampton, The Amazon Provinces of Peru (1889), también contó con imágenes de población indígena basadas en fotografías.

5 Varias de las fotografías reproducidas en este álbum firmado por Fernando Garreaud fueron anteriormente publicadas en Lima llustrado y Monitor Popular o corresponden a los clichés que Charles Kröehle —en sociedad con George Huëbnerhabía elaborado a finales de la década de 1880. Algunos de estos clichés etnográficos también fueron exhibidos en la sección de antropología de la Exposición Universal de Chicago (1893). 
un álbum con vistas de la selva central destinada a la Oficina de Propaganda, Inmigración e Informaciones establecida, ese mismo año, en París ${ }^{6}$. La colección fotográfica fue remitida a la Dirección de Fomento hacia enero de 1912 y se componía de vistas de establecimientos colonos, la población indígena y, sobre todo, destacaba la importancia de las obras viales que permitían alcanzar los ríos navegables amazónicos.

Estas tempranas colecciones fotográficas también fueron utilizadas por instituciones y privados, como la Sociedad Geográfica de Lima, instituciones misioneras o los ministerios de Fomento y Relaciones Exteriores, en exposiciones y conferencias abiertas al público nacional, en Lima y algunas ciudades del interior, a fin de despertar el interés empresarial, filantrópico 0 académico por el oriente peruano. Por ejemplo, los clichés de Meyer fueron usados por Víctor 0. Salomón, diplomático peruano comisionado en Inglaterra y Australia, quien tuvo a bien organizar distintas conferencias sobre el Perú, tanto en el extranjero como en algunas ciudades del interior, utilizando constantemente las fotografías que fue recolectando de los fondos gubernamentales.

Entrado el siglo xx, una vez que se tomó conciencia de la creciente importancia que adquiría la divulgación de las imágenes fotográficas ante diferentes públicos, aumentó el valor que alcanzaron los materiales generados por la Junta de Vías Fluviales dentro de las políticas oficiales ${ }^{7}$. Sus informes fueron publicados $y$, ampliamente ilustrados, remitidos a diversas instituciones públicas y centros de investigación en el país y el extranjero. Asimismo, estos materiales fueron incorporados en otros textos de divulgación y propaganda estatal, y reproducidos en diversos periódicos y revistas ilustradas en el país.

Un caso especial que demuestra el uso de todas estas estrategias de publicidad visual fue la Exposición Interna- cional de Gomas Elásticas y comercios anexos, que tuvo lugar en el Royal Agricultural Hall de Londres, entre junio y julio de 1911. En dicho certamen, el pabellón peruano ofreció a los concurrentes publicaciones ilustradas sobre la selva peruana (v. gr. The Old and new Perú de M.R. Wright; Últimas exploraciones ordenadas por la JVF (...); Amazon provinces of Peru as a Field for European Immigration de $\mathrm{H}$. Guillaume; Noticias sobre los gomales en la región del Monzón, publicado por la Voce d'Italia) y un conjunto de fotografías, en gran formato, la mayoría de ellas ofrecidas por el cauchero Julio César Arana, sobre sus posesiones en el Putumayo ${ }^{8}$.

Por último, algunas de estas fotografías del territorio y población amazónica (v. gr. Kröehle, Meyer, Silvino Santos, Lira) fueron editadas en una serie de tarjetas postales, en blanco y negro y coloreadas en tricromía, alcanzando amplia difusión en el público limeño durante las primeras dos décadas del siglo $x x^{9}$.

Figura 2. En el Putumayo. Portada del diario La Crónica de Lima, edición del 29 de agosto de 1912. Reproduce fotografías de las caucherías del Putumayo, obra de Silvino Santos, de la "Colección Arana".

Numerosos medios peruanos publicaron las fotografías remitidas por el cauchero J.C. Arana para ilustrar distintas notas sobre la región amazónica peruana. Estas imágenes sirvieron, a su vez, para reforzar la imagen progresista y patriótica de este empresario frente a la opinión pública nacional, vinculando sus actividades al posicionamiento del Perú en los confines del territorio nacional amazónico.

6 Esta dependencia estatal abrió sus puertas al público el 28 de julio de 1911, bajo la dirección de Carlos Larrabure y Correa, quien, en una nota publicada al año siguiente señalaba que "en los salones destinados al público, como en los reservados al personal de la oficina se han colocado mapas y fotografías de nuestras principales ciudades, de las instalaciones industriales [...], vistas de la montaña y de las obras de arte más interesantes de los ferrocarriles del Perú" (Larrabure, 1912, pp. 2-3).

7 Institución estatal creada en 1901, con el fin de organizar una serie de exploraciones e investigaciones en los territorios selváticos del sur peruano, en especial el Urubamba y el Madre de Dios, aunque también tuvieron actividades en otras regiones de la selva peruana. La diversas comisiones de la Junta entregaron una serie de informes, los cuales, según indicaciones explícitas en los contratos firmados, fueron acompañados de imágenes fotográficas. Las colecciones generadas en estos viajes fueron utilizadas para ilustrar las diversas publicaciones de la Junta sobre el río Madre de Dios.

8 El corpus fotográfico elaborado por la Casa Arana fue obra de un grupo de profesionales (Eugène Robuchon, Manuel Rodríguez Lira, Silvino Santos) que fueron contratados por esta empresa para construir un relato visual que evidenciara el esfuerzo y "sacrificio" que significaba llevar la "civilización" — merced al transporte fluvial, el comercio y la nacionalización de los indígenas por medio del trabajo- a los confines del territorio nacional. Parte de este material sirvió, asimismo, para la elaboración de un film propagandístico, El Oriente peruano, expuesto en la sala del cine Excelsior de Lima, en agosto de 1921, ante un público que incluía a altos mandos militares, funcionarios públicos, representantes de la prensa limeña y el presidente de la república Augusto B. Leguía.

9 Editadas por empresarios como Eduardo Polack, Lira \& Gil y Luis Sablich. 


\section{Reapropiación contemporánea de las imágenes históricas}

El centenario del denominado Escándalo del Putumayo, referido al destape público de la explotación de indígenas que trabajaron en la empresa del caucho entre 1880 y 1920, sobre todo en la selva nororiental del Perú, en el año 2012, fue clave para fomentar la discusión entre intelectuales y activistas de los derechos de los pueblos indígenas acerca del proceso histórico que ha atravesado la población indígena amazónica y su vinculación al resto de la sociedad nacional. Si bien el debate se mantuvo en un grupo reducido, tuvo relativo impacto en el ámbito cultural, pues fue lo que impulsó la implementación de las exposiciones analizadas. En este contexto, distintas exposiciones y publicaciones organizadas en la capital del país permitieron al público limeño encontrarse con algunas de estas tempranas fotografías de la Amazonía. Entre estas imágenes, las más recurrentes corresponden a los clichés de J. Charles Kröehle \& Georg Huëbner, así como la denominada Colección Arana, compuesta por imágenes de Silvino Santos y Manuel R. Lira.

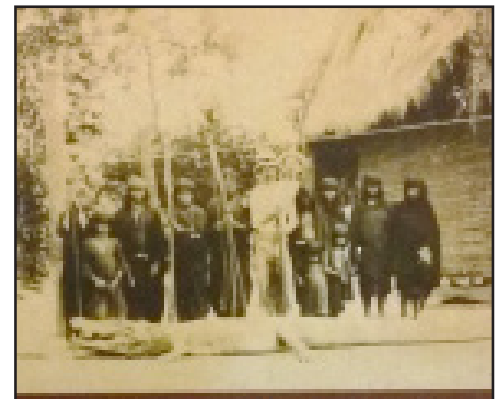

La Amazonía de Ch. Kroehle

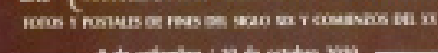

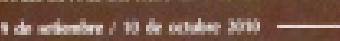

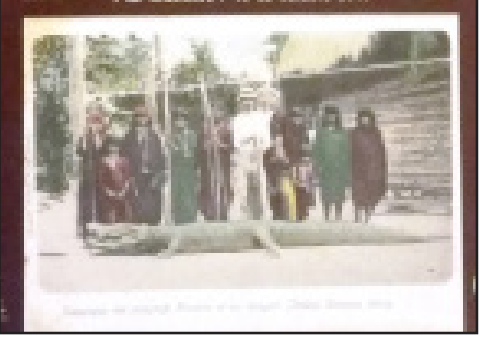

Las imágenes desplegadas en estas exhibiciones marcan un estilo similar. Por un lado, registros etnográficos de indígenas, y por otro, retratos colectivos que evidencian la supuesta relación de la población indígena con representantes de un mundo urbano representado a través de la presencia de empresarios caucheros, funcionarios/comisionados estatales 0 misioneros católicos (Ver figuras 1, 2, $3,6)$. En el marco de un análisis antropológico, en estos casos, la fotografía representa una diferencia extrema, que fortalece valores opuestos en cada uno de los personajes, por un lado, civilización y modernidad y, del otro, salvajismo e inmoralidad reflejada en la desnudez del indígena.

Para esta época, los contenidos de las imágenes no necesitaban representar situaciones explícitamente salvajes o grotescas para fijar significados de otredad. Según el imaginario colonial predominante, alimentado por diversos soportes, además del fotográfico, por textos y diarios de viajeros, así como la vitalidad del discurso decimonónico del progreso, los significados de las imágenes estaban dados de antemano. Las fotografías de representación de la otredad, con contenidos explícitos, en su mayoría performativas y fotomontajes, sirvieron para reforzar esos conceptos ya afianzados socialmente.

Así, estas imágenes, aparentemente amigables, esconden una relación tensa -incluso violenta - entre los indígenas y la población que representa el mundo

\section{El bestiario domesticado}

Tríptico de la exposición La Amazonía de Ch. Kröehle. Fotos y postales de fines del siglo XIX y comienzos del XX, en el Centro Cultural Inca Garcilaso de la Vega, de la cancillería, 2010. Fotografía y tarjeta postal de la colección Humberto Currarino.

Figura 3. Portada del material elaborado para distribuir entre los visitantes de la muestra. Presenta una fotografía original y una postal, en tricolor, editada por Eduardo Polack. En la imagen, Ios fotógrafos Kröehle (con rifle) y Huëbner, ambos en el centro de la imagen, rodeados de indígenas, aparentemente asháninkas, en el Ucayali. En el frente, el cuerpo de un lagarto, presa de caza. moderno. Conflicto especialmente evidente en el marco del boom del caucho. Los famosos horrores del caucho fueron ampliamente registrados por diversas fuentes, como el famoso Libro Azul, Informe del cónsul británico Roger Casement (Chirif, 2012).

Si bien la temática reflejada en estas fotografías históricas va más allá de la explotación cauchera, Ilama la atención el uso constante de este marco referencial dentro de las exposiciones, que insisten en resaltar una imagen de lejanía cultural entre la población amazónica y el resto de la sociedad nacional. Esta referencia termina profundizando la exotización y subordinación del universo indígena frente a lo moderno y empresarial, hecho reclamado por el Estado-nación.

Desde una mirada al corpus visual, nos preguntamos ¿cómo se leen las fotos del pasado como documentos históricos?, ¿cuáles son los efectos de esta reapropiación contemporánea de fotografías históricas, con respecto a la población indígena y el territorio amazónico? Finalmente, hasta qué punto estas exhibiciones fotográficas sobre el indígena y el territorio amazónico refuerzan una visión crítica de la sociedad nacional, que empodere a los grupos indígenas en sus demandas frente al Estado, o si, en lugar de ello, reafirman, ante el público que congregan, los mismos tópicos de exotismo, lejanía y pasividad, reflejo de la visión que se tenía de la Amazonía en el contexto en que estas imágenes fueron generadas.

\section{Valor de verdad de las imágenes históricas}

Ante la pregunta acerca de la repercusión que tienen las exhibiciones contemporáneas que incorporan fotografías históricas de indígenas, es necesario partir analizando del rol que cumple la fotografía en la sociedad, específicamente, el uso de la imagen como documento histórico. 


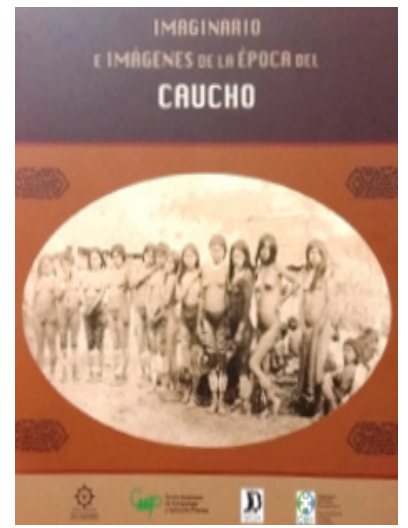

\section{El cuerpo de mujer exhibido}

Tríptico de la exposición Imaginario e imágenes de la época del caucho. CC. Garcilaso, organizado por el CAAAP, IWGIA y OEI, 2012. Fotografía de Silvino Santos. Colección Alberto Chirif. Figura 4.- Grupo de jóvenes huitotos pintadas y formadas, aparentemente, antes de un realizar un baile ante comisionados oficiales. El cuerpo desnudo de la mujer indígena, expuesto y sexualizado.

Susan Sontag ha señalado que las fotografías proveen la mayor parte del conocimiento que las personas tenemos sobre la manera de ver el pasado (Sontag, 2006). Desde su creación, a mediados del siglo XIX, la fotografía fue considerada una herramienta tecnológica capaz de representar la realidad tal como era. La representación sería así el producto incuestionable de un aparato productor de conocimiento y no de la mano del hombre (Edwards, 1992). Esta forma de entender la fotografía ha cambiado, profundamente, en más de ciento cincuenta años de experiencia fotográfica. Este cambio da un giro para entender la producción fotográfica de un formato objetivo, científico y proveedor de verdad, a una tecnología y formato de representación parcial basada en la posición del autor, su subjetividad y los alcances tecnológicos de los propios aparatos fotográficos (Pink, 2006; Banks y Morphy, 1999).

Está consensuado que el análisis de la fotografía, histórica y contemporánea, depende del entendimiento del contexto social, político y cultural en que las imágenes fueron hechas (Burke
2005, Kossoy, 2001). Lo mismo para entender su proceso de producción, circulación, consumo (Poole, 2000) e incluso, las prácticas de apropiación, acumulación y colección. De ese modo, se entienden los documentos fotográficos como construcciones sociales de alta utilidad para determinados objetivos políticos e ideológicos, tal como ocurrió con las imágenes de la población indígena amazónica producidas entre fines del siglo XIX e inicios del XX (Biffi, 2009; Emission y Smith, 2000; Edwards, 1992). No obstante, parece que estos argumentos no son evidentes en el consumo de fotografías históricas. Si bien las fotografías históricas, al igual que el resto de documentos visuales y textuales, son fuentes de información sobre la historia, estos clichés suelen ser consideradas fuentes de información irrefutables sobre el pasado. Ello es consecuencia de la tradición de asumir la fotografía como una herramienta objetiva, dando un valor único de verdad a las imágenes que la tecnología produce. La propia definición de fotografía como documento suponía, entonces, una noción de verdad oficial e incuestionable (Majluf y Wuffarden, 2001).

Esta postura desdice el hecho de que la fotografía, desde su creación, también estuvo politizada e integrada a ideales de modernización y progreso (Biffi, 2012). Un claro ejemplo de ello son los clichés fotográficos analizados en el presente artículo. Las fotografías que el cauchero Julio C. Arana mandó elaborar con reconocidos fotógrafos de la época, como Eugène Robuchon, Manuel Rodríguez Lira o Silvino Santos, para registrar su obra civilizatoria con los indígenas y su labor nacionalista en la frontera amazónica. Lo mismo ocurre con los álbumes encargados por la Dirección de Fomento sobre las regiones, recursos e industrias del Perú, promocionando espacios prístinos, amplios y vacíos, dejando de lado cualquier consideración a la existencia de una sociedad indígena previamente establecida.

Así, la fotografía histórica, repropiada en un contexto contemporáneo, debe ser analizada desde un doble enfoque, como fuente de información primaria y como forma de representación de mensajes políticos y sociales específicos de una época. Esta es, justamente, la manera en que debemos tratar las fotos amazónicas seleccionadas para las exhibiciones en cuestión.

\section{Archivos fotográficos y exposición}

Las exhibiciones amazónicas contemporáneas pudieron ejecutarse en la medida que existían los materiales fotográficos históricos accesibles, catalogables y en buen estado. El éxito del cumplimiento de estas premisas respondió al interés, sobre todo de coleccionistas privados, de albergar estos materiales y ponerlos en valor. Dicha puesta en valor parte de un proceso de descontextualización de las imágenes. Sacar las fotografías de su uso inicial para reposicionarlas y repropiarlas con fines contemplativos, estéticos e históricos frente a audiencias contemporáneas. Por ejemplo, pasar del uso de la fotografía como propaganda estatal para entrar en un nuevo tratamiento de contemplación estética de la imagen como documento histórico en un espacio cultural.

La capacidad para poner en valor el material fotográfico histórico ha dependido de su pertenencia a alguna colección, de recursos posteriores y curaduría que las seleccionen para su exhibición. El conjunto de fotos seleccionadas tiene un lugar porque otros clichés fueron dejados de lado, proponiendo una narrativa, una forma de mirar el pasado, que es apropiada en el presente y espera proyectarse al futuro (Schwartz \& Cook, 2002). Aquí, entonces, vale la pena reflexionar sobre el poder que ejercen los agentes involucrados en la producción fotográfica de la época: los fotógrafos, los empresarios que solicitan la producción fotográfica, los coleccionistas y los productores contemporáneos. La responsabilidad de la representación de una supuesta realidad no debe recaer en las fotografías únicamente, sino en la curaduría. 


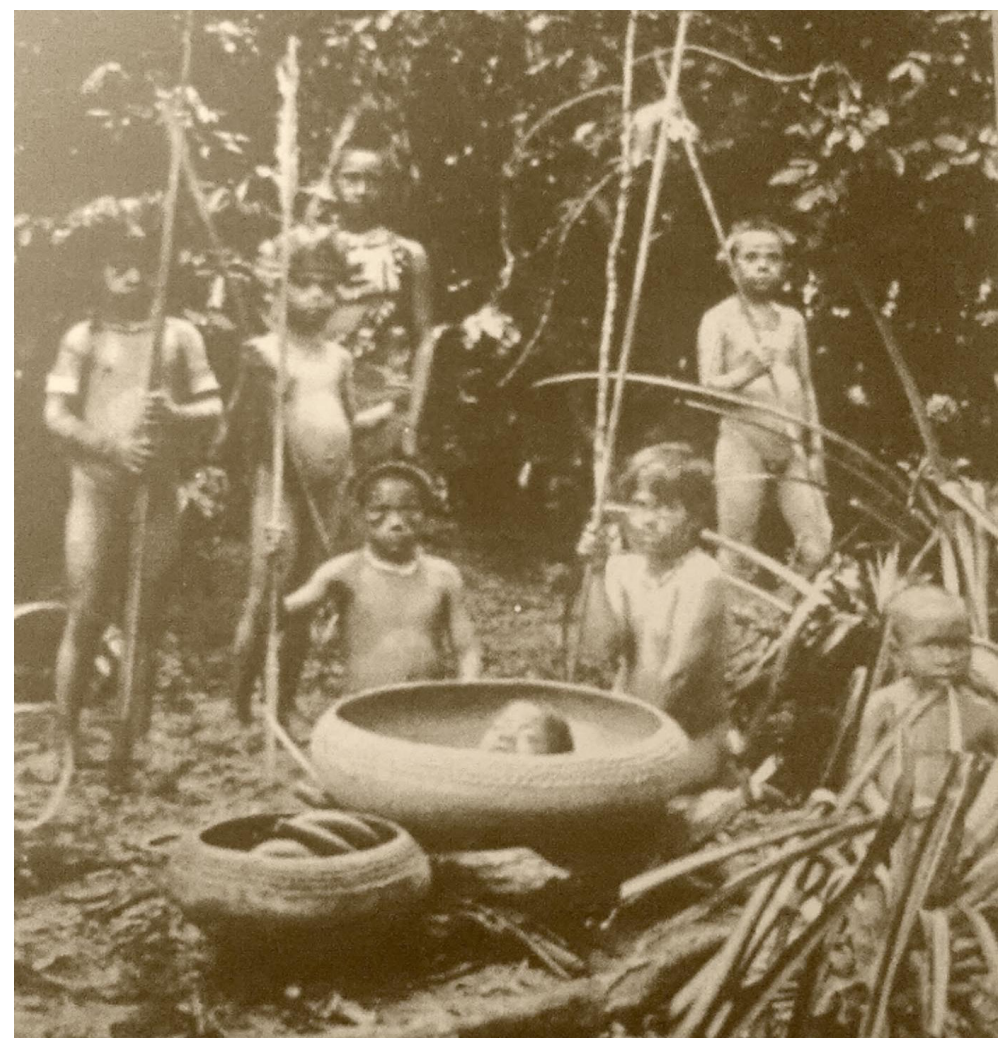

Figura 5. Indios caníbales del Putumayo, contiene la leyenda: "Los indios de este distrito, incluso muy jóvenes, se hacen la guerra entre ellos, y comen la carne de los que han matado. Los dientes son llevados como trofeos, como se ve en la tinaja" (en la tinaja se ve una cabeza sobresaliendo). En Customs of the World (Londres, 1913).

En este marco, las fotografías históricas pueden terminar proyectando en el público, a falta de fotografías alternativas y de otras lecturas, una mirada artificial del pasado amazónico. Aun cuando se trata de imágenes producidas con un enfoque político específico, progresista y nacionalista, que buscan reflejar la presencia estatal más allá de la frontera interior e incorporar a la Amazonía, en cuanto población indígena y territorio, dentro del proyecto nacional (La Serna, 2012).

Por otro lado, la reapropiación contemporánea de estas imágenes continúa con la tradición fotográfica de entender los clichés como documentos verdaderos, fuentes históricas fidedignas que tienen valor de verdad en sí mismas. Esta situación fortalece la forma de representación de los indígenas amazónicos como personajes subordinados que se mantienen al margen de la sociedad mayor. Una excepción interesante fue la muestra Imágenes e Imaginarios de la Época del Caucho en el C.C. Garcilaso de la Vega, donde los curadores llaman la atención sobre los fotomontajes para fortalecer la dicotomía, muy de moda en la época, entre civilización y salvajismo. Específicamente, la Figura 5 muestra una cabeza humana dentro de una tinaja en el suelo, rodeada de niños desnudos que portan lanzas. Esta imagen supone fortalecer el perfil caníbal de los huitotos para justificar la cruzada civilizatoria iniciada por los caucheros en los confines del bosque amazónico peruano. Cabe resaltar que este tipo de fotografías tuvieron estrecha relación con la producción de textos de viajes de la época, por ejemplo, el libro de Thomas Whiffen, The North West Amazon. Notes of months spent among cannibal tribes (Londres, 1915), que, además, incluye imágenes de huitotos, boras y ocainas, cuya producción es apropiada por el autor.

La falta de cuestionamiento al valor de verdad histórica de las fotografías puede reafirmar en el público una narrativa conservadora sobre la socie- dad indígena, que seguiría siendo vista como una población estática, dócil y subordinada, gracias al trabajo de los representantes de la sociedad moderna. Esto se hace aún más evidente en las fotografías grupales, donde aparecen comisionados, empresarios, expedicionarios; es decir, los progresistas, es decir, gente que viene de las ciudades, acompañados de los indígenas. Estas imágenes, además, servían para marcar las distancias sociales y culturales, es decir, para visibilizar el lugar que cada quien ocupaba en la sociedad, donde el escalón inferior siempre corresponde a los pueblos indígenas, exóticos y salvajes.

Cuando la fotografía histórica es apropiada y exhibida en tiempos recientes resulta difícil cuestionar la capacidad que esta tiene para reflejar, de manera verídica, el contexto social en que fueron generadas, llevándonos, en muchos casos, a reafirmar visiones estáticas y pasadistas sobre la población indígena amazónica. La museografía tiene la tarea fundamental de introducir nuevos elementos para repensar las transformaciones en la identidad cultural indígena contemporánea. De no ejecutarse esta acción, el público difícilmente saldrá de su zona de confort y de sus viejas imágenes de exotismo y otredad. Es decir, no podrá cuestionar los elementos del imaginario común sobre el indígena, lo amazónico y el proceso histórico presentado en las imágenes, a menos de que las leyendas que las acompañen lo expongan claramente, evitando reafirmar viejos tópicos preexistentes en el público. Ejemplo de ello es el caso de los caníbales que se exponen en base a los clichés de Kröehle en el CC. Garcilaso de la Vega, o los huachipairis, de Luis Alviña, que aparecen en la Estación Cultural Desamparados.

Esto es lo que justamente ocurre con las imágenes presentadas en la exposición Serpiente de Agua, de 2003, donde, a diferencia de los objetos de cultura material y las imágenes fotográficas contemporáneas que expresan la agencia y vitalidad de las poblaciones indígenas en actividades cotidianas (v. gr. un niño amahuaca de espaldas sonriendo a la cámara; una joven mujer amaraeki jugando 
con su mascota mientras cuida a su bebé; niños asháninkas sonriendo, surcando el río Perené, una mujer asháninka acongojada, velando a un familiar muerto), las imágenes históricas muestran al indígena en poses tipológicas y hieráticas, como si se estuviera construyendo un muestrario de la otredad interior a los ojos del público (Landolt y Surrallés, 2003). ¿Cómo entender estas dos maneras de imaginar al indígena, con un siglo de diferencia, si los clichés expuestos no empujan al observador a hacer este ejercicio de reflexión? zónico, no necesariamente lograron el cometido e, incluso, reinciden en una imagen de pasividad y diferencia, aun cuando, en ambos casos, conjuntamente a las exposiciones se publicaron textos que integraron las fotografías dentro de reflexiones más concienzudas. Por su lado, el público termina consumiendo imágenes y reseñas que no contextualizan, de manera efectiva, el escenario y los objetivos con que fueron producidas las fotografías.

Estas imágenes en exhibiciones contemporáneas deberían ser herra- mientas argumentativas para fomentar la presencia de los indígenas como actores políticos que reivindiquen sus derechos, para exigir una revisión de las formas tradicionales de representación de la población indígena y para visibilizar, en un ámbito mayor de la sociedad, el proceso complejo de inclusión de este colectivo al proyecto nacional. Las exhibiciones aquí analizadas, desde el enfoque propuesto, son un punto de partida, pero no suficiente. Ello implica desarrollar investigaciones con estudios de audiencia en las próximas exhibiciones de este estilo ${ }^{11}$.

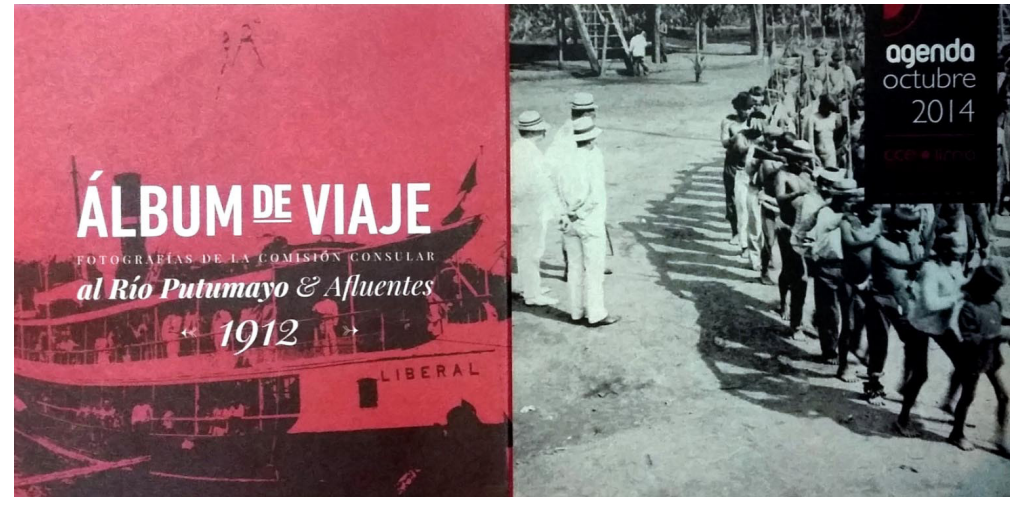

Figura 6. Álbum de Viaje. Fotografías de la Comisión consular al río Putumayo y afluentes. 1912. Díptico de la exposición en el Centro Cultural de España, 2014.

Por ello, la contextualización del proceso de construcción de imágenes y sus usos originarios, en estos casos, claramente con fines políticos, abre la oportunidad de repensar y reinterpretar, a la luz de la historia actual, las estrategias de representación de lo indígena para proponer miradas reflexivas y revisionistas de la propia historia nacional, como ha sido el objetivo de algunas exposiciones sobre pueblos indígenas y sociedades colonizadas organizadas el extranjero ${ }^{10}$.

Si bien las exposiciones Serpiente de Agua (2003) y Viaje consular (2014) tienen el objetivo expreso de cuestionar la mirada tradicional que el público urbano ha construido del sujeto ama-

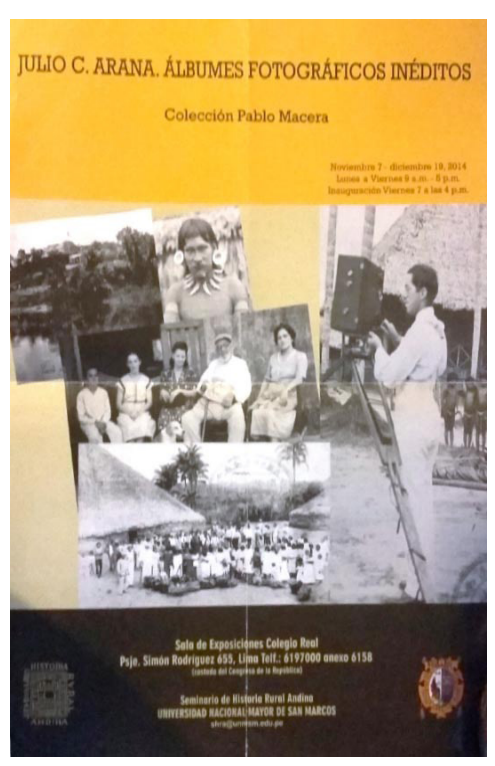

Figura 6. Afiche de la exposición J. César Arana: Álbumes fotográficos inéditos, de la colección Pablo Macera, en el Colegio Real, Seminario de Historia Rural Andina de la Universidad Nacional Mayor de San Marcos, 2014.

En esta exposición se trabaja la figura del empresario J.C. Arana. La paradoja es que si bien se problematiza la relación violenta que la explotación cauchera estableció con la población indígena, en las imágenes ofrecidas en los afiches se insiste en el rol secundario y complementario del indígena frente al sujeto occidental —-fotógrafo o cauchero- relación de subordinación que, justamente, la exposición desea confrontar.

10 En especial vale la pena revisar la muestra Exhibiciones: La invención del salvaje, en el Museo de quai Branly, de París, en el 2011. Esta muestra fue organizada, según sus propios curadores, con el interés de "descolonizar la mirada sobre el extranjero" (Blanchard, Boëtsch \& Snoep, 2011).

11 Existen algunos casos de artistas plásticos, indígenas y no indígenas que se han apropiado de estas imágenes históricas usándolas de referencia en sus pinturas, sobre todo las que se relacionan a la época del caucho (Chirif y Cornejo, 2009). Estos trabajos podrían despertar otras miradas de resistencia, de activismo o de reivindicación que terminen por derruir los viejos tópicos de pasividad y lejanía que el público citadino limeño ha construido sobre la población amazónica. 
validez de los contextos discursivos en que estas fueron originalmente producidas. El material fotográfico sobre la Amazonía, en la medida que no sale de la zona de confort del espectador, no se discute.

Las muestras fotográficas pueden ser excelentes puntos de partida para reflexionar, dentro de la esfera pública nacional, los procesos históricos y las condiciones sociales y culturales actuales de la población indígena. Ello nos exige, sin embargo, sacar al espectador de la zona de confort, discutir acerca de lo que hay de verdad -y lo que no- en una fotografía. Implica reconocer que, en la imagen, lo que se representa es una referencia etnográfica del pasado. La docilidad de las fotografías desconecta a la población indígena de su propio proceso histórico y sigue presentándola, ante el público urbano y costeño, como la permanente amenaza al sueño del progreso, al tiempo que su humanidad y, por lo tanto, su capaci- dad de ser integrados a la comunidad nacional, sigue estando puesta en tela de juicio. Las etnias y los personajes, en la medida que conforman una otredad, son intercambiables unos por otros (Bhabha, 1999) y, tal como ocurrió con las postales de inicios del siglo xx, no debería sorprender que los huitotos, retratados en las caucherías del Putumayo, volvieran a aparecer ante nosotros representando los conflictos socioambientales recientes en la selva del Camisea o del río Corrientes.

\section{Bibliografía}

Banks, M., y H. Morphy. (1999). Rethinking Visual Anthropology. New Haven: Yale University Press.

Bhabha, H. (1999). The Other Question. En J. Evans y S. Hall (eds.). Visual Culture: The Reader. London: Sage Publications in Association with the Open University.

Biffi, V. (2009). Amazonian Photographic Archive: Visual Discourses of the Peruvian Amazon from the Late 19th Century to the Early 20th Century [A dissertation submitted to the Department of Sociology, in partial fulfilment of the requirements for the MSc Culture and Society]. Londres: London School of Economics and Political Science.

Biffi, V. (2012). Notas para la construcción de un archivo sobre historia visual amazónica. En G. Cánepa (ed), Imaginación visual y cultura en el Perú. Lima: Fondo Editorial de la Pontificia Universidad Católica del Perú.

Blanchard, P., Boëtsch, G., y Jacomijn Snoep, N. (2011). Exhibitions. L'invention du sauvage. Paris: Musée du quai Branly.

Burke, P. (2005). Visto y no visto. El uso de la imagen como documento histórico. Barcelona: Cultura Libre.

Chirif, A. (2012). El Libro Azul. Informe de Roger Casement y otras cartas sobre las atrocidades en el Putumayo. Lima: CAAAP/IWGIA.

Chirif, A,. y Cornejo, M. (2009). Imaginario e imágenes de la época del caucho. Los sucesos del Putumayo. Lima: CAAAP.

Edwards, E. (1992). Anthropology and Photography. 1860-1920. New Haven: Yale University Press y The Royal Anthropological Institute.

Emmison, M., y Smith, P. (2000). Researching the Visual: Images, Objects, Contexts and Interactions in Social and Cultural Inquiry. London: SAGE.

Flores, R. (2012). Etnografía visual y colonización cauchera. En G. Cánepa (ed.), Imaginación visual y cultura en el Perú. Lima: Fondo Editorial de la Pontificia Universidad Católica del Perú.

Kossoy, B. (2001). Fotografía e historia. Buenos Aires: La Marca.

Landolt, G., y Surrallés, A. (2003). Serpiente de agua. La vida indígena en la Amazonía. Lima: Fundación Telefónica.

Larrabure, C. (1912). La Oficina de Inmigraciones y Propaganda del Perú en Europa. Anales de la Dirección de Fomento, (7), 2-3.

Larrabure, C. (1905). Colección de leyes, decretos y resoluciones y otros documentos oficiales referentes al Departamento de Loreto (...) (t. I). Lima: Imprenta de la Opinión Nacional.

La Serna, J. C. (2013). La domesticación visual de la montaña. Imágenes del territorio y población amazónica proyectadas por El Perú Ilustrado (1887-1892). Nueva Coronica. Revista de la Escuela de Historia de la Universidad Nacional Mayor de San Marcos, (2), 377-394. 
La Serna, J. C. (2012). Visiones de progreso, otredad y fronteras internas en la construcción de la Amazonía peruana. Una aproximación a los discursos visuales sobre la "montaña" a fines del siglo xIx. En G. Cánepa (ed.), Imaginación visual y cultura en el Perú. Lima: Fondo Editorial de la Pontificia Universidad Católica del Perú.

La Serna, J. C. (2105). The Forest as Cliché: Otherness, Progress, and Internal Frontiers in Early Photography from the Amazon. American Anthropologist, 117(4), 795-812.

Majluf, N., y Wuffarden, L. E. (2001). La recuperación de la memoria: Perú, 1842-1942. Madrid: Fundación Telefónica.

Pink, S. (2006). The Future of Visual Anthropology: Engaging the Senses. Londres: Routledge.

Poole, D. (2000). Visión, raza y modernidad. Una economía visual del mundo andino de imágenes. Lima: Sur, Casa de Estudios del Socialismo.

Schwartz, J., y Cook, T. (2002). Archives, Records, and Power: The Making of Modern Memory. Archival Science, (2), 1-19.

Sontag, S. (2006). Sobre fotografía. México, D. F.: Alfaguara.

Whiffen, T. (1915). The North West Amazon. Notes of Months Spent Among Cannibal Tribes. Londres: Constable \& Company. 